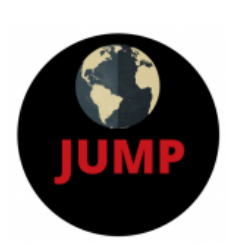

ISSN: 2574-3465 Print/ ISSN: 2574-3481 Online Volume 4, Issue 1 (2020), pp. 20-43

(C) Journal of Underrepresented and Minority Progress

http://ojed.org/jump

\title{
Preliminary Investigation of Efforts to Improve Awareness of Racial Microaggressions on Campus
}

\author{
Brea M. Banks \\ David F. Adams \\ Cedric Williams \\ Dakesa Piña \\ Illinois State University, USA
}

\begin{abstract}
Exposure to racial microaggressions negatively impacts the well-being of people of color. Researchers examined responses to a bystander workshop implemented to combat racial microaggressions at a Predominantly White Institution. Participants attended training sessions and completed several surveys prior to and after the workshop for 7 weeks. Results indicate that participants obtained and maintained knowledge presented during the bystander workshop. Significant differences for gender and racial status were identified surrounding the degree to which participants reported observing microaggressions on campus throughout the 7 weeks of the study. Data also indicate that colorblind racial attitudes predicted participant satisfaction with the program, as well as an underrepresented racial identity. Implications and future directions for research are discussed.
\end{abstract}

Keywords: bystander, counseling, microaggression 


\section{INTRODUCTION}

First defined by Pierce and colleagues (1977), microaggressions are "subtle, stunning, often automatic, and nonverbal exchanges" directed toward people of color that contribute to a "never-ending burden" (p.65). They have also been defined as "subtle insults (verbal, nonverbal, and/or visual) directed toward people of color, often automatically or unconsciously" (Sólorzano, Ceja, \& Yosso, 2000, p.60). In spite of Pierce and colleagues' (1978) early definition, microaggressions and unconscious racism initially received scant attention among researchers. In recent years, evidence has demonstrated the serious implications of microaggressions on the physical and psychological health of people of color.

Racial microaggressions are a nuanced and subtle form of racism that manifests in identifiable ways (Sue \& Sue, 2008). Sue and colleagues (2007) identified three forms of racial microaggressions: microassault, microinsult, and microinvalidation. First, a microassault is an overt act or statement made by a perpetrator with the explicit intent to do harm to the target of the racial microaggression (Sue \& Sue, 2008; Sue et al., 2007). Examples include public use of racial slurs and delaying service people of color in a restaurant (Sue \& Sue, 2008). Second, microinsults entail interactions that denigrate a person's racial identity or cultural background (Sue \& Sue, 2008; Sue et al., 2007). For example, an employee asking a colleague of color how they got their job or an interviewer openly voicing surprise that a person of color would have had outstanding training or experiences are examples of microinsults (Sue \& Sue, 2008; Sue et al., 2007). In recent studies, participants have reported other examples of microinsults, such as being treated as a second-class citizen, having their cultural values pathologized, other assuming they have a criminal status or background, and having their intelligence, competence, or authority questioned or challenged (Ogunyemi et al., 2019; Pittman, 2012; Weber et al., 2017). Lastly, microinvalidations are comments or behaviors that invalidate a person of color's internal psychological experiences and realities (Sue \& Sue, 2008; Sue et al., 2007). Examples include treating a person as an alien in their own land, the myth of meritocracy, and denial of individual racism (Ogunyemi et al., 2019). The messages conveyed are that people of color are not welcome, ought to be excluded or treated differently, are not qualified, or have received special treatment as a result of their societal position (Pittman, 2012; Sue et al., 2007). The multiple forms of microaggressions reinforces the continued presence of racism within society. 
It should be noted that microaggression can be relevant to any subordinate identity that an individual holds, such as sexual orientation, gender, ability, and so on. However, the focus of the current study surrounds race-based aggressions. Further, we are limiting our conceptualization of microaggression to the slights that are truly unintentional and subtle. As such, we will not discuss microassaults, as we see these as macro-level indignities that are purposeful in nature.

\section{LITERATURE REVIEW}

\section{Impact of Racial Microaggressions on Health}

It has been well documented that racial microaggressions have significant, negative impacts on the health and well-being of people of color. For example, a recent investigation found that racial microaggressions significantly contributed to poorer health outcomes for people of color, such as emotional struggles, low energy, social inferiority, increased pain arousal, decreased overall health, and impairment in ability to fulfill roles (Nadal et al., 2017). Recent evidence has also illustrated the physical stress experienced as a result of racial microaggressions has a negative impact on health outcomes among a Latinx population (Anderson \& Finche, 2017). Racial microaggressions have also been found to increase diabetes distress by contributing to poorer dietary and physical exercise habits (Sittner et al., 2018). Similarly, exposure to these indignities hinder the quality and duration of sleep over time (Ong et al., 2017).

In addition to impacting overall health, the extant literature has illustrated a strong connection between racial microaggressions and poor psychological outcomes. A recent meta-analysis confirmed the strong relationship between microaggressions and adjustment outcomes (Lui \& Quezada, 2019). Studies utilizing Asian American individuals demonstrate that microaggressions significantly contribute to lower self-esteem, poorer psychological adjustment, increased negative affect, and increased somatic symptoms (Ong et al., 2013; Thai et al., 2017). Further demonstrating the significant consequences of racial microaggressions, a recent investigation found that exposure to racial microaggressions significantly predicted symptoms of depression and the presence of suicidal ideation (O'Keefe et al., 2015). Similarly, recent evidence has supported a relationship between racial 
microaggressions and decreased well-being, mediated by cultural mistrust (Kim et al., 2017). Specifically, increased experiences of racial microaggressions contribute to increased cultural mistrust (i.e., suspicion of White individuals), with in turn decreases participant well-being.

\section{Microaggressions in the Academic Environment}

A great deal of the microaggression literature has focused on the experiences of university students. College students endure a variety of environmental stressors: moving away from parents, relational conflicts, career pressure, and enduring physiological changes. For students of color, additional stressors may be present that surface as a result of their racial/ethnic identity. For example, Black students, at Predominantly White Institutions (PWIs) face "challenges such as pressure to conform, racial conflict, lack of support, institutional racism, social isolation, and inequitable treatment by university personnel" (Grier-Reed et al., 2016, p.185). Also relevant to college adjustment, researchers contend that the exposure to microaggressions may result in students of color feeling excluded and avoided (Wesselmann et al., 2016). Regardless of intent, these experiences may leave people of color feeling invisible to students, faculty, and staff members on their college campuses, which may contribute to social and academic withdrawal (Houshmand et al., 2014).

Further, exposure to microaggressions impacts students' ability to learn (Embrick et al., 2017). Ideally, the collegiate environment is a space that fosters supportive learning and growth; however, the reality of racial microaggressions is that students of color have uniquely different experiences compared to their White counterparts. African American students report experiencing discomfort, feeling drained, and a negative self-concept as a result of racial microaggressions on campus (Solórzano et a., 2000). Further, research suggests that exposure to racial microaggressions negatively impacts the mental health and academic success of students of color (Keels et al., 2017). More specific to college student's academic performance, research suggests that exposure to microaggressions leads to the immediate depletion of cognition in college students of color (Author, 2019).

Within the realm of higher education, retention and persistence is an important issue for universities, personnel in student affairs, and for the academic culture of institutions. In an early study, Giles-Glee (1989) noted the concerns of Black students are multifaceted and cannot be addressed by 
singular programs or offices. More recent studies have drawn appropriate attention to contextual, environment, and institutional variables impacting student retention. Racial microaggressions are the product of institutions that reaffirm White supremacy via statues, celebrated figures, or a lack of diversity in various public and social spaces (Embrick et al., 2017). For students of color, "microaggressions are the common occurrence that reminds them that, despite their academic achievement, they do not belong in academia" (Nakaoka \& Ortiz, 2018, p.73). A recent study found a significant negative correlation between racial microaggressions and persistence attitudes, suggesting that when racial microaggressions are prominent, one's attitudes are less focused on persistence at that academic institution (Hernandez \& Villodas, 2019). Attention to environmental context is imperative. In light of higher retention rates for African American students at historically Black colleges and universities (HBCUs), such institutions are uniquely providing experiences and resources that are not had at PWIs (Rodgers \& Summers, 2008). Recent data have indicated that Black students reported "higher levels of microaggressions as the percent of the student body that was White increased" (Keels et al., 2017, p.1336). When environmental support structures are put into place, retention rates increase, drawing attention to the importance of physical safe space as well as individual persons as models for adaptively coping with racial microaggressions in a collegiate setting (GrierReed, 2016).

\section{Microinterventions and the Current Study}

One example of environmental support includes efforts to educate White individuals, with specific focus on the implementation of programs to change reactions to racially microaggressive behavior. In light of the preponderance of evidence that racial microaggressions have immediate and long-term deleterious consequences for the health and psychological wellbeing of people of color, attention must to be paid to confronting racial microaggressions when they occur. People of color are faced with the heavy burden of routine bombardment of these experiences; navigating the psychological consequences of such interactions; developing coping strategies to use based on context and situation; determining whether to respond to racial microaggressions when they arise; and the cognitive and emotional outcomes of these responding or not responding (Sue et al., 2019). For these reasons, it is certainly important to arm targets of racial 
microaggressions with resources to intervene, as well as lessen the impact of these experiences.

In service of creating a society where racial microaggressions are less widespread, it would be prudent to focus attention on microintervention strategies that may be used specifically by those who witness racial microaggressions. Scully and Rowe (2009) describe a bystander as an individual who "sees or otherwise becomes aware of behavior that appears worthy of comment or action" (p.1). Attention to bystander behavior is important, as Sue and colleagues (2019) note that little attention has been paid to the role of bystanders who witness racial microaggressions, calling for future researchers to study the impact of microintervention trainings for these groups. Further, the bystander model presents as promising to address racial microaggressions in light of evidence of its utility in addressing sexual assault and violence prevention (Banyard et al., 2007; Burn, 2009; Scully \& Rowe, 2009). A bystander can significantly impact the outcome of a potentially harmful situation by intervening in support of a victim, as opposed to victim blaming (Banyard et al., 2007; Scully \& Rowe, 2009). Within this context, the bystander model is aimed at primary prevention (Burn, 2009) and seeks to include the larger community in the process (Banyard et al., 2007). Attention be must paid to educating bystanders, particularly White individuals who make up a significant portion of the population and may have a less nuanced understanding of racial bias (Sue et al., 2019).

Because researchers have just begun to explore the use of microinterventions or strategies to combat microaggressions (Sue et al., 2019), we aimed to examine the impact of a workshop that was implemented to help attendees define racial microaggressions and develop strategies they might use to respond when witnessing these incidents. As a preliminary study, the primary focus was on the following hypotheses that were developed prior to data collection: (1) engagement in the workshop will increase participant knowledge of microaggressions immediately following the training, (2) participants will demonstrate maintenance of obtained knowledge, and (3) engagement in the workshop will improve participant awareness of microaggressions on campus. Colorblind racial attitudes (i.e., racism does not exist and race does not impact the experiences of people of color) were also explored, because researchers were interested in exploring how such attitudes would impact participants engagement in the training. Finally, researchers posed the following exploratory research 
question: (1) do participants find engagement in the workshop satisfying?

\section{RESEARCH METHOD}

\section{Participants}

Data were obtained from 53 students at a mid-size public Midwestern university, where $8 \%$ of the student body were students of color, and $57 \%$ of the population was female. Participant age ranged from 18 to 26 years $(M=$ 20.55, $S D=1.84$ ). Participants' year in school was as follows: $28.30 \%$ freshmen, $18.90 \%$ sophomores, $24.50 \%$ juniors, $22.60 \%$ seniors, and 5.70 $\%$ graduate students. Demographic data were gathered surrounding race/ethnicity (i.e., $64.20 \%$ White, $11.30 \%$ Black/African American, 9.40\% Asian, $7.50 \%$ Latinx, and 7.50\% Bi/Multiracial), gender (i.e., $64.20 \%$ women and $35.80 \%$ men) and sexual orientation (i.e., $81.10 \%$ straight and $18.90 \%$ lesbian, gay, or bisexual).

\section{Design}

Researchers utilized a quasi-experimental, repeated measures design to assess changes before and after the implementation of the workshop. The developed measures described below provide insight into the variables examined.

\section{Measures}

Pre-workshop Assessment

Survey items were developed to assess participant obtained and maintained knowledge of microaggression as a concept and relevant to the specific experiences of students of color on their campus (see Table 1). This survey also included items to assess demographic characteristics, prior exposure to the term microaggression (i.e., "before today, had you previously heard of the term microaggression?") and the Color-blind Racial Attitudes Scale (CoBRAS).

The COBRAS is a 20 -item measure developed by Neville and colleagues (2000) to examine dimensions of color-blind racial attitudes or 
colorblindness, which support an ideology that racial differences should not matter or that individuals should not "see color." Participants respond to items on a 6-point Likert scale ranging from 1 ("strongly disagree") to 6 ("strongly agree"). Analyses in the initial validation of the measure yielded 3 composites (i.e., Unawareness of Racial Privilege, Institutional Discrimination, Blatant Racial Issues) and a total CoBRAS score. Cronbach's alphas for the 4 factors was acceptable, as they ranged from .76 to .91 . Reliability for the current study was also acceptable, as the total CoBRAS score was .92.

\section{Post-workshop and Follow-up Assessment}

Eight surveys were crated to examine maintained knowledge of microaggressions and participants' awareness of microaggressive exchanges on campus across 7 weeks. First, the Post-workshop Assessment included the same knowledge items from the Pre-workshop Assessment that are listed in the Table 1. Second, the 7 Follow-up Assessment surveys included the following multiple-choice (i.e., "none, "1," "2," and "3 or more") items: "how many racially microaggressive exchanges did you witness on campus this past week? Such interactions may have occurred among faculty, staff, or students in any setting on campus (e.g., social spaces, classroom, work spaces). Other items were also included that were not assessed as part of the current study. Specifically, if 1 or more incidents were reported, the following items prompted a description of each exchange (i.e., "describe what happened," "how did you respond," and "where did this occur"). If "none" was selected, no additional items were presented. Finally, Follow-up Assessment surveys for weeks 3 and 7 also included the same knowledge items from the Preworkshop Assessment and Post-workshop Assessment that are listed in Table 1, as well 6 Likert scale satisfaction items (e.g., this training increased my knowledge about racial microaggressions).

\section{Procedure}

\section{Recruitment}

After securing approval from their university's Institutional Review Board, researchers recruited participants via mass emails that were distributed to university students who had opted in to receive advertisement emails for research studies on campus. Students were informed that their participation would involve attendance at a 2-hour workshop and completion surveys that 
would be distributed at different times over the course of 8 weeks. They were also informed that they would be eligible to receive gift cards as incentive for their completion of the administered surveys. Those interested were directed to complete an eligibility measure via the online survey tool Qualtrics. This survey assessed demographic characteristics (i.e., year in school, age, gender, race/ethnicity) and student availability for the day and time the workshops were scheduled. Given availability and the use of random selection, researchers invited 60 participants to attend 1 of 3 sessions. A total of 7 students neglected to attend their assigned session, yielding 18 participants in the first group, 19 in the second, and 16 in the last group.

\section{Bystander Training Program}

The utilized program was implemented by 2 of the current authors (a Black/African American man and White man) who were also providers at the sampled institution's University Counseling Center (UCC). The UCC received permission from the University of Arizona C.A.T.S. Life Skills Program to modify their Step Up! Bystander Intervention Program (2010) to specifically address racial microaggressions (The University of Arizona C.A.T.S. Life Skills Program, 2010). Step Up! is a bystander intervention training program that teaches student-athletes to proactively navigate difficult situations, such as depression, discrimination, hazing, and sexual assault. The aim is to create awareness of helping behaviors, increase participant motivation to help, enable skill development, increase confidence when responding to problems, and ensure the safety and well-being of those on campus. A major tenant of this program encourages bystanders to assume personal responsibility to act when they see a problematic event. This program has been adopted by the National Collegiate Athletic Association (NCAA) and other universities working with non-athlete student populations (The University of Arizona C.A.T.S. Life Skills Program, 2010).

Utilizing the Step Up! model, a 90-minute bystander training was developed that focused on the experiences of racial microaggressions on campus. First, training material included definitions and examples of racial microaggressions were presented to increase participant knowledge. Next, data were presented to increase participant awareness of the prevalent nature of racial microaggressions on their campus. The final portion of the workshop included psychoeducation surrounding the use of three approaches used by the Step UP! campaign - individuation (e.g., helping the person see others as 
individuals as opposed to members of a disliked group), recategorization (e.g., inviting the person to see a targeted group as similar to others with shared goals), and confrontation (e.g., pointing out inconsistencies in a person's statements or actions and identifying biases) - to combat to microinsults and microinvalidations. This training utilized interactive components, as participants engaged in small and large group discussions where they discussed personal bias, prior experiences witnessing and/or experiencing racial microaggressions, and their typical responses to racial microaggressions. Because the focus was on unintentional expressions of microaggression, interventions to address microassaults were not part of this training.

It should be mentioned that the program was designed for the sampled institution's UCC to implement across campus at the request of faculty/staff (e.g., class or department presentations) and student groups (e.g. Registered Student Organizations). However, to facilitate experimental control, data for the current study only included participants who were recruited via the methods described above. The program was implemented with each of the 3 recruited groups on 3 different Fridays, with sessions lasting 90 to 120 minutes depending on questions and comments offered by participants. Surveys were administered via an online survey tool (Qualtrics) or using paper and pen, depending on participant preference. Participants completed the Pre-workshop Assessment upon arrival before the start of the training. Prior to the completion of any items, participants created a 5-digit code that was used as their identifier for each survey to preserve anonymity. Participants completed the Post-workshop Assessment immediately after the workshop before they were dismissed. Ten days after the workshop and the following six Mondays, researchers emailed the weekly Follow-up Assessment surveys to participants to complete via Qualtrics.

\section{RESULTS}

Researchers recoded some variables prior to conducting primary analyses to help facilitate interpretation of the data. First, researchers created the following variables given participant responses to demographic items: racial status (i.e., White $=0$ and Black/African American, Latinx, Native American, or multiracial $=1)$, gender $(\operatorname{man}=0$ and woman $=1)$, sexual orientation (straight $=0$ and gay, lesbian, or bisexual $=1$ ). It should be noted that racial status was coded as described for two reasons. First, the small 
sample size, which was racially diverse given the institution's demographic composition, did not allow for examinations of the five racial groups that were reported. Further, although we acknowledge that non-White individuals of varying racial backgrounds have different experiences and in turn different reactions to racism and microaggression, researchers were interested in exploring their interpretation of the workshop in comparison to White participants who had not had any personal exposure to racial microaggression. The item that assessed the degree to which participants previously witnessed microaggressions on campus was dummy coded from Likert format (i.e., never to always). Specifically, never was recoded to 0 , while all other responses were recoded as 1.

A knowledge composite was created using participant responses to the 6 survey items in Table 1 that assessed understanding of microaggressions as part of the Pre-workshop Assessment, Post-workshop Assessment, and Follow-up Assessment for weeks 3 and 7. Participants earned one point for each correct multiple-choice item (5 points possible) and for each type of microaggression listed (i.e., microinsult, microinvalidation, and microassault; 3 points possible). An Awareness composite was created by adding the number of microaggressive exchanges participants reported witnessing via the Follow-up Assessment for weeks 1 through 7. Finally, a Satisfaction composite was obtained by adding the relevant 6 items on the Follow-up Assessment for week 7. It should be noted that some participants missed the completion deadline for the Follow-up Assessment surveys. These missing data, along with other descriptive statistics, can be found in Table 2.

Several analyses were conducted to answer the posed research questions surrounding workshop goals to increase knowledge, improve awareness, and gauge program satisfaction. First, researchers hypothesized that engagement in the workshop would increase participant knowledge of microaggressions immediately following the training and that this knowledge would be maintained throughout the duration of the study. Preliminarily, researchers conducted a three-way analyses of variance (ANOVA), which indicated that there were no significant differences in participant Knowledge based on their racial status $[F(1,45)=1.70, p=.20]$, gender $[F(1,45)=.26$, $p=.61]$, sexual orientation $[F(1,45)=.51, p=.48]$, or whether or not they had heard of racial microaggression prior to the workshop $[F(1,45)=1.76, p$ $=.19]$. Further, linear regression analyses demonstrate that $\operatorname{CoBRAS}[b=-$ $.19, t(51)=-.80, p=.43]$ composite scores did not predict scores on the Preworkshop Assessment. 
The primary hypotheses were supported given the results of a oneway repeated measures ANOVA (see Tables 3 and 4). Mauchly's test indicated that the assumption of sphericity was met $\chi^{2}(5)=1.85, p=.87$, so degrees of freedom were not corrected. There was a significant main effect for time, $F(3,141)=70.68, p<.01, \eta^{2}=.61$. Pairwise comparisons that included a Bonferroni adjustment demonstrated simple main effects when comparing Pre-workshop Assessment Knowledge to Post-workshop Assessment ( $p<.01)$, Follow-up Assessment at week $3(p<.01)$, and Followup Assessment Knowledge at week $7(p<.01)$.

Regarding awareness of microaggressive exchanges on campus, a two-way ANOVA was conducted to examine racial and gender differences (see Table 5). Specifically, a significant interaction was identified for Awareness $\left[F(1,49)=4.27, p<.04, \eta^{2}=.08\right]$, as White women $(M=3.52$, $S D=2.61)$ reported witnessing significantly more racial microaggressions throughout the duration of the study, as compared to White men $(M=1.45$, $S D=1.63)$, women of color $(M=1.36 ., S D=1.63)$, and men of color $(M=$ $1.88, S D=1.46)$. Two-way ANOVAs were also conducted to examine Satisfaction (see Table 6). A significant difference for gender was identified $\left[F(1,45)=11.15, p<.01, \eta^{2}=.20\right]$, as women $(M=4.50, S D=.66)$ provided ratings indicating greater satisfaction as compared to men $(M=3.73, S D=$ .82). A significant difference for racial status also surfaced $[F(1,45)=5.01$, $\left.p=.03, \eta^{2}=.10\right]$, as people of color $(M=4.60, S D=.61)$ found the program more favorable than White participants $(M=4.08, S D=.83)$. Further, linear regression analyses demonstrated that elevated color-blind racial attitudes predicted lower Satisfaction scores, $b=-.58, t(48)=-5.84, p<.01$, and explained a significant proportion of the variance in ratings, $\mathrm{R}^{2}=.42, F(1,48)$ $=34.13, p<.01$.

\section{DISCUSSION}

To our knowledge, this is the first study to investigate the impact of a program aimed to train bystanders in responding to racial microaggressions. While the impact of racial microaggressions has been well-detailed in the literature, no previous study has investigated programming focused on immediate response and prevention. We utilized our modified version of the University of Arizona's Step Up! program that specifically addressed responses to racial microaggression. We found that participants' knowledge of microaggression improved immediately following the workshop and that 
obtained knowledge was maintained well after the training. This finding is underscored by the fact that knowledge is foundational for understanding how racism and discrimination affects oneself and others (Sue et al., 1992) and is particularly relevant to bystander training, as a bystander must know and recognize that an event has occurred before one is able to respond (Scully \& Rowe, 2009). Data surrounding social justice ally development has also supported the notion that "learning about the experiences of individual target group members" is crucial to ally development (Broido, 2000, p. 15).

\section{Gender Differences in Awareness of Racial Microaggressions}

In response to the question posed by Sue and colleagues (2019) regarding the interplay of cultural variables in responding to racial prejudice, the present study yielded significant findings. Specifically, when compared to men, women were more likely to report having witnessed a racial microaggression prior to the implementation of the workshop. The presence of gender differences among participants witnessing racial microaggressions is consistent with previous research, as women better recognize complex and covert forms of discrimination (Basford, Offermann, \& Behrend, 2014). Further, adolescent girls and those from underrepresented racial backgrounds were more likely to identify the presence of microaggressions than men and White participants (Grossman \& Porche, 2014). Another plausible explanation to this finding surrounding women's nuanced ability to recognize microaggressions is the potential of their own personal experiences with sexist discrimination. The presence of sexism is an everyday reality uniquely faced by women, which poses challenges when navigating various facets of one's life. This would suggest that women's lived experiences greatly influence their ability to recognize the presence of less overt forms of discrimination. This explanation was also offered by Grossman and Porche (2014), who stated that people who have "experienced systemic barriers may be more attuned to the treatment of underrepresented groups due to prior experiences with stereotyping or discrimination" (p. 717). Conversely, due to occupying more social privilege based on gender-identity, men are less likely to experience discrimination based on gender. Therefore, they may be inclined to only notice more explicit displays of discrimination and are thus less likely to report witnessing subtle forms of microaggressions due to a lack of recognizing the event as discrimination. 
Results of the study also indicate that White women reported witnessing significantly more racial microaggressions compared to White men, women of color, and men or color. Researchers have argued that "White men and women experience Whiteness differently," as White men are more likely to perceive those from unrepresented racial backgrounds as a threat to their social standing and privileges (Yueng et al., 2013, p.28). This, however, does not explain the finding that White women observed more slights when compared to men and women of color. While initially surprising, these data may be reflective of mundane extreme environmental stress (MEES) experienced by people of color at PWIs (Peters \& Massey, 1983). Specifically, although we know that racial microaggressions negatively impact the functioning of people of color, these experiences may be interpreted as mundane because people of color experience them frequently (Carroll, 1998). As such, it may be the case that participants of color in the current study reported observing fewer instances of racial microaggression given the frequency of their own experiences. On the other hand, the novelty of the concept, lack of personal experience with racial microaggressions, and greater openness to expanding their racial awareness may have produced a surge in awareness for White women that was maintained throughout the study. These findings suggest an important interaction between race and gender, especially for White men and women, that ought to be considered for future bystander trainings.

\section{Racial Colorblindness}

Regarding program satisfaction, women and people of color provided more favorable ratings of the program as compared to men and White participants. Additionally, colorblind racial attitudes predicted lower satisfaction scores. These results highlight the importance of focusing on White individuals when engaging bystanders and allies in discussions of racial microaggressions. Reason and colleagues (2019) emphasize the role of Whiteness when discussing their model of racial justice ally development. Specifically, they found that greater reflections on Whiteness contributed to higher levels of racial justice actions, whereas fewer reflections were associated with students generally interpreting Whiteness as skin color and lack of engagement in social justice action. The current program invited White participants to critically examine racial prejudice and increase their knowledge about racial microaggression, which contradicts the acculturation 
model of White supremacy and racial hierarchy (Liu et al., 2019). White individuals perpetuate the acculturation of people of color by upholding colorblindness ideologies, which justify social inequities while leaving White people devoid of personal responsibility (Neville et al., 2013). Relevant to the current study, it follows that individuals who provided higher ratings of colorblindness reported less value or satisfaction in the program, as opposed to those who may recognize the important role that race continues to play in social disadvantage.

\section{LIMITATIONS}

As discussed, the current study adds an important contribution to the research literature. Nonetheless, certain limitations exist that must be considered. First, we only examined colorblindness and the mentioned demographic characteristics as predictors. However, it is possible that other variables that were not included as part of the current study may better explain the identified relationships (e.g., attitudes about social justice, racial centrality). Regarding external validity, it is important that the results of the current study not be generalized to other populations that do not mirror the current sample. Specifically, data were collected at a Predominantly White Institution. Although research suggests that individuals experiences racial microaggressions across settings (e.g., Historically Black Colleges and Universities, Hispanic Serving Colleges and Universities, elementary and high schools, the workplace), results of the current study cannon be generalized to these settings.

Limitations also exist surrounding the implementation bystander workshop and collected data. Specifically, although researchers controlled the developed material for the workshop and presenters, participants across the three sessions may have experienced the workshops differently depending on the groups' engagement (e.g., questions asked, examples provided). This would not only influence the content of the training, but also the amount of time spent in the session. Further, a larger and more diverse sample may have produced more robust findings. It may also have proved beneficial to obtain pre- and post-workshop data surrounding colorblind racial attitudes, to assess the degree to which involvement in the research study influence these beliefs. Finally, we failed to collect information regarding participant majors due to restrictions placed by the Institutional Review Board. This data may have 
provided insight into a pre-existing variable that may have influenced outcomes of the participating in the workshop.

\section{Future Directions}

To sum, active bystander behaviors and allyship will only occur when "inhibitions are overcome, and when these skills are learned, practiced, and rehearsed" (Sue, 2019, p. 140). However, it is prudent that future investigations devote specific attention to White racial identity development of participants in trainings focused on microaggression. The inclusion of White individuals in trainings like the one described in the current study is necessary because those in positions of power can often promote more equitable and inclusive environments (Spanierman \& Smith, 2017).

While the present study introduced participants to microintervention strategies outlined by Sue and colleagues (2019), time was not devoted to practice and rehearsal of these skills. Engagement in behavioral rehearsal may help address personal inhibitors that may serve as potential barriers to action. A recent study by Poteat and colleagues (2019) found self-efficacy as a significant variable impacting bystander behaviors and speak to the importance of empowering participants to feel capable and effective when witnessing a racial microaggression. Research on bystander training to address sexual violence has also illustrated that skills deficits represent significant barriers to action (Burn, 2009). From our perspective, bystander trainings must include opportunities to practice intervening when individuals witness microaggressions occurring across settings.

\section{REFERENCES}

Anderson, K.F., \& Finch, J.K. (2017). The role of racial microaggressions, stress, and acculturation in understanding Latino health outcomes in the USA. Race and Social Problems, 9, 218-233. https://doi.org/10.1007/s12552$\underline{017-9212-2}$

Banyard, V. L., Moynihan, M. M., \& Plante, E. G. (2007). Sexual violence prevention through bystander education: an experimental evaluation. Journal of Community Psychology, 35, 463-481. https://doi.org/10.1002/jcop.20159

Basford, T.E., Offerman, L.R., \& Behrend, T.S. (2014). Do you see what I see? Perceptions of gender microaggressions in the workplace. Psychology of 
Women Quarterly, 38, 340-349.

https://doi.org/10.1177/0361684313511420

Broido, E. M. (2000). The development of social justice allies during college: A phenomenological investigation. Journal of College Student Development, 41, 3-18.

Burn, S. M. (2009). A situational model of sexual assault prevention through bystander intervention. Sex Roles, 60, 779-792. https://doi.org/10.1007/s11199-008-9581-5

Carroll, G. (1998). Mundane extreme environmental stress and African American families: A case for recognizing different realities. Journal of Comparative Studies, 29, 271-284. https://doi.org/10.3138/jcfs.29.2.271

Embrick, D.G., Dominguez, S., \& Karsak, B. (2017). More than just insults: Rethinking sociology's contribution to scholarship on racial microaggressions. Sociology Inquiry, 87, 193-206. https://doi.org/10.1111/soin.12184

Giles-Gee, H.F. (1989). Increasing the retention of black students: A multimethod approach. Journal of College Student Development, 30, 196-200.

Grier-Reed, T., Arcinue, F., \& Inman, E. (2016). The African American student network: An intervention for retention. Journal of College Student Retention: Research, Theory, \& Practice, 18, 183-193. https://doi.org/10.1177/1521025115584747

Grossman, J.M., \& Porche, M.V. (2014). Perceived gender and racial/ethnic barriers to STEM success. Urban Education, 49, 698-727.

https://doi.org/10.1177/0042085913481364

Hernandez, R.J., \& Villodas, M. (2018). Collectivistic roping responses to racial microaggressions associated with Latina/o college persistence attitudes. Journal of Latinx Psychology, 7, 76-90. https://doi.org/10.1037/lat0000107

Houshmand, S., Spanierman, L.B., \& Tafarodi, R.W. (2014). Excluded and avoided: Racial microaggressions targeting Asian international students in Canada. Cultural Diversity and Ethnic Minority Psychology, 20, $377-$ 388. https://doi.org/10.1037/a0035404

Keels, M., Durkee, M., \& Hope, E. (2017). The psychological and academic costs of school based racial and ethnic microaggressions. American Educational Research Journal, 54, 1316-1344. https://doi.org/10.3102/0002831217722120

Kim, P.Y., Kendall, D.L., \& Cheon, H.S. (2017). Racial microaggressions, cultural mistrust, and mental health outcomes among Asian American college students. American Journal of Orthopsychiatry, 87, 663-670. https://doi.org/10.1037/ort0000203

Liu, W.M., Liu, R.Z., Garrison, Y.L., Kim, J.Y.C., Chan, L., Ho, Y.C.S.H., \& Yeung, C.W. (2019). Racial trauma, microaggressions, and becoming racially innocuous: The role of acculturation and white supremacist 
ideology. American Psychologist, 74, 143-155.

https://doi.org/10.1037/amp0000368

Nadal, K.L., Griffin, K.E., Wong, Y., Davidoff, K.C., \& Davis, L.S. (2017). The injurious relationship between racial microaggressions and physical health: Implications for social work. Journal of Ethnic \& Cultural Diversity in Social Work, 26(1-2), 6-17. https://doi.org/10.1080/15313204.2016.1263813

Nakaoka, S., \& Ortiz, L. (2018). Examining racial microaggressions as a tool for transforming social work education: The care for critical race pedagogy. Journal of Ethnic \& Cultural Diversity in Social Work, 27(1), 72-85. https://doi.org/10.1080/15313204.2017.1417947

Neville, H.A., \& Awad, G.H., Brooks, J.E., Flores, M.P., \& Bluemel, J. (2013). Color-blind racial ideology: Theory, training, and measurement implications in psychology. American Psychologist, 68, 455-466. https://doi.org/10.1037/a0033282

Neville, H. A., Lilly, R. L., Duran, G., Lee, R. M., \& Browne, L. (2000). Construction and initial validation of the color-blind racial attitudes scale (CoBRAS). Journal of Counseling Psychology, 47, 59-70. https://doi.org/10.1037/0022-0167.47.1.59

O'Keefe, V.M., Wingate, L.R., Cole, A.B., Hollingsworth, D.W., \& Tucker, R.P. (2015). Seemingly harmless racial communications are not so harmless: Racial microaggressions lead to suicidal ideation by way of depression symptoms. Suicide and Life-Threatening Behavior, 45, 567-576. https://doi.org/10.1111/sltb.12150

Ogunyemi, D., Clare, C., Astudillo, Y. M., Marseille, M., Manu, E., \& Kim, S. (2019). Microaggressions in the learning environment: A systematic review. Journal of Diversity in Higher Education. Advance online publication. https://doi.org/10.1037/dhe0000107

Ong, A.D., Burrow, A.L., Fuller-Rowell, T.W., Ja, N.M., \& Sue, D.W. (2013). Racial microaggressions and daily well-being among Asian Americans. Journal of Counseling Psychology, 60, 188-199.

Ong, A.D., Cerrada, C., Lee, R.A., \& Williams, D.R. (2017). Stigma consciousness, racial microaggressions, and sleep disturbance among Asian Americans. Asian American Journal of Psychology, 8, 72-81. https://doi.org/10.1037/a0031736

Peters, M. F., \& Massey, G. (1983). Mundane extreme environmental stress in family stress theories: The case of Black families in White America. Marriage \& Family Review, 6(1-2), 193-218. https://doi.org/10.1300/J002v06n01 10

Pierce, C.M., Carew, J.V., Pierce-Gonzalez, D., Wills, D. (1977). An experiment in racism: TV commercials. Education and Urban Society, 10, 61-87. 
Pittman, C. T. (2012). Racial microaggressions: The narratives of African American faculty at a predominately white university. The Journal of Negro Education, 81(1), 82-92.

Poteat, V.P., Slaatten, H., \& Breivik, K. (2019). Factors associated with teachers discussing and intervening against homophobic language. Teacher and Teacher Education, 77, 31-42. https://doi.org/10.1016/j.tate.2018.09.006

Reason, R.D., Millar, E.A.R., \& Scales, T.C. (2019). Toward a model of racial justice ally development. Journal of College Student Development, 46, 530-546.

Rodgers, K.A., \& Summers, J.J. (2008). African American students at predominately white institutions: A motivational and self-systems approach to understanding retention. Educational Psychology Review, 20, 171-190. https://doi.org/10.1007/s10648-008-9072-9

Scully, M., \& Rowe, M. (2009). Bystander training within organizations. Journal of the International Ombudsman Association, 2, 1-9.

Sittner, K.J., Greendfield, B.L., Walls, M.L. (2018). Microaggressions, diabetes distress, and self-care behaviors in a sample of American Indian adults with type 2 diabetes. Journal of Behavioral Medicine, 41, 122-129. https://doi.org/10.1007/s10865-017-9898-z

Solórzano, D., Ceja, M., \& Yosso, T. (2000). Critical race theory, racial microaggressions, and campus racial climate: The experiences of African American college students. The Journal of Negro Education, 69, 60-73.

Spanierman, L., \& Smith, L. (2017). Roles and responsibilities of White allies: Implications for research, teaching, and practice. The Counseling Psychologist, 45, 606-617.

Step UP! Bystander Intervention Program. (2010). Retrieved June 14, 2019, from http://stepupprogram.org/.

Sue, D.W., Alsaidi, S., Awad, M.N., Claeser, E., Calle, C.Z., \& Mendez, N. (2019). Disarming racial microaggressions: Microintrvention strategies for targets, white allies, and bystanders. American Psychologist, 74(1), 128-142. https://doi.org/10.1177/0011000017717712

Sue, D. W., Arredondo, P., \& McDavis, R. J. (1992). Multicultural counseling competencies andstandards: A call to the profession. Journal of Multicultural Counseling and Development, 20(2), 64-88. https://doi.org/10.1002/j.2161-1912.1992.tb00563.x

Sue, D. W., Capodilupo, C. M., Torino, G. C., Bucceri, J. M., Holder, A. M. B., Nadal, K. L., \& Esquilin, M. (2007). Racial microaggressions in everyday life: Implications for clinical practice. American Psychologist, 62(4), 271286. https://doi.org/10.1037/0003-066X.62.4.271

Sue, D.W., \& Sue, D. (2008). Counseling the culturally diverse: Theory and practice $\left(5^{\text {th }}\right.$ ed.). John Wiley \& Sons, Inc. 
Thai, C. J., Lyons, H. Z., Lee, M. R., \& Iwasaki, M. (2017). Microaggressions and self-esteem in emerging Asian American adults: The moderating role of racial socialization. Asian American Journal of Psychology, 8(2), 83-93. https://doi.org/10.1037/aap0000079

Weber, A., Collins, S.A., Robinson-Wood, T., Zeko-Underwood, E., \& Poindexter, B. (2017). Subtle and severe: Microaggressions among racially diverse sexual minorities. Journal of Homosexuality, 65, 540-559. https://doi.org/10.1080/00918369.2017.1324679

Yueng, J.G., Spanierman, L.B., \& Landrum-Brown, J. (2013). "Being White in a multicultural society": Critical Whiteness pedagogy in a dialogue course. Journal of Diversity in Higher Education, 6, 17-32. https://doi.org/10.1037/a0031632 


\section{APPENDIX}

Table 1

Knowledge Survey Items

1. Based on data gathered in 2016, staff members are more likely to report as the source of harassment or discriminatory behavior:
a. Colleagues
b. Subordinates
c. Supervisors or senior colleagues
d. Students

2. Based on data gathered in 2016 , students are more likely to report _ as the source of harassment or discriminatory behavior:
a. Other students
b. Faculty or professors
c. Staff members
d. Work colleagues or supervisors

3. Based on data gathered in 2016, students are more likely to report that harassment and discrimination occur:
a. At on campus jobs
b. In social spaces
c. In class

4. List the 3 types or classifications of microaggressions:

5. Which includes an example of a microinsult?

a. Sheree puts her backpack in the seat next to her on the bus when a Black man looks to sit there.

b. Ray urges his friend not to always play the "race card" in arguments.

c. Cory asks his Latinx classmate how to say something in Spanish.

d. Kortni notices racial slurs written on the bathroom wall at a bar.

e. A and $\mathrm{C}$

f. B and D

6. Which includes an example of a microinvalidation?

a. Unwittingly, Professor Bo never calls on the Black women in his statistics class.

b. Jim argues that Black people are being too sensitive about non-Black people using the n-word.

c. Rose's counselor tells her that she understands her experiences as a multiracial person, but that it's most important that she focus on her identity as a human being.

d. Simon tells a joke about Asian women being bad drivers.

e. A and D

f. $B$ and $C$

Note. Correct answers are bolded. 
Table 2

Descriptive Statistics across Composite $(n=53)$

\begin{tabular}{llll}
\hline & $n$ & $M$ & $S D$ \\
\hline Knowledge Composite & & & \\
Pre-workshop Assessment & 53 & 2.49 & 1.51 \\
Post-workshop Assessment & 53 & 5.58 & 1.61 \\
Follow-up Assessment Week 3 & 50 & 5.84 & 1.61 \\
Follow-up Assessment Week 7 & 50 & 5.72 & 1.73 \\
Awareness Composite & & & \\
Follow-up Assessment Week 1 & 51 & 0.98 & 1.07 \\
Follow-up Assessment Week 2 & 51 & 0.65 & 0.74 \\
Follow-up Assessment Week 3 & 50 & 0.46 & 0.73 \\
Follow-up Assessment Week 4 & 49 & 0.49 & 0.71 \\
Follow-up Assessment Week 5 & 52 & 0.29 & 0.61 \\
Follow-up Assessment Week 6 & 50 & 0.42 & 0.70 \\
Follow-up Assessment Week 7 & 50 & 0.42 & 0.76 \\
Satisfaction Composite & & & \\
Follow-up Assessment Week 7 & 50 & 4.25 & 0.79 \\
\hline
\end{tabular}

Table 3

Repeated Measures ANOVA for Knowledge Composite

\begin{tabular}{llcccccc}
\hline & $S S$ & $d f$ & $M S$ & $F$ & $P$ & $\eta^{2}$ \\
\hline 1 & Sphericity Assumed & 385.43 & 3.00 & 128.48 & 70.68 & $<0.01$ & 0.60 \\
& Greenhouse-Geisser & 385.43 & 2.92 & 132.05 & 70.68 & $<0.01$ & 0.60 \\
& Huynh-Feldt & 385.43 & 3.00 & 128.48 & 70.68 & $<0.01$ & 0.60 \\
& Lower-bound & 385.43 & 1.00 & 385.43 & 70.68 & $<0.01$ & 0.60 \\
2 & Sphericity Assumed & 256.32 & 141.00 & 1.82 & & & \\
& Greenhouse-Geisser & 256.32 & 137.19 & 1.87 & & & \\
& Huynh-Feldt & 256.32 & 141.00 & 1.82 & & & \\
& Lower-bound & 256.32 & 47.00 & 5.45 & & & \\
\hline
\end{tabular}

Note. 1 = Time, 2 = Error 
Table 4

Bonferroni Adjustment Pairwise Comparison for Knowledge Composite $(n=48)$

\begin{tabular}{llccc}
\hline Time 1 & Time 2 & $\begin{array}{c}\text { Mean } \\
\text { Difference }\end{array}$ & $S E$ & $p$ \\
\hline Pre & Post & -3.21 & 0.29 & $<0.01$ \\
& Week 3 & -3.29 & 0.28 & $<0.01$ \\
\multirow{2}{*}{ Post } & Week 7 & -3.31 & 0.29 & $<0.01$ \\
& Pre & 3.21 & 0.29 & $<0.01$ \\
& Week 3 & -0.08 & 0.27 & 1.00 \\
Week 3 & Week 7 & -0.10 & 0.25 & 1.00 \\
& Pre & 3.29 & 0.28 & $<0.01$ \\
& Post & 0.08 & 0.27 & 1.00 \\
Week 7 & Week 7 & -0.02 & 0.26 & 1.00 \\
& Pre & 3.31 & 0.29 & $<0.01$ \\
& Post & 0.10 & 0.25 & 1.00 \\
& Week 3 & 0.02 & 0.26 & 1.00 \\
\hline
\end{tabular}

Table 5

ANOVA for Awareness Composite

\begin{tabular}{lcccccc}
\hline & $S S$ & $d f$ & $M S$ & $F$ & $p$ & $\eta^{2}$ \\
\hline Intercept & 192.65 & 1 & 192.65 & 43.33 & $<0.01$ & 0.47 \\
POC & 8.62 & 1 & 8.62 & 1.94 & 0.17 & 0.04 \\
Gender & 6.91 & 1 & 6.91 & 1.55 & 0.22 & 0.03 \\
POC * Gender & 18.98 & 1 & 18.98 & 4.27 & 0.04 & 0.08 \\
Error & 217.89 & 49 & 4.45 & & & \\
Total & 575 & 53 & & & & \\
\hline
\end{tabular}

Table 6

ANOVA for Satisfaction Composite

\begin{tabular}{lcccccc}
\hline & $S S$ & $d f$ & $M S$ & $F$ & $p$ & $\eta^{2}$ \\
\hline Intercept & 662.57 & 1 & 662.57 & 1398.90 & $<0.01$ & 0.97 \\
POC & 2.38 & 1 & 2.38 & 5.01 & 0.03 & 0.10 \\
Gender & 5.28 & 1 & 5.28 & 11.15 & $<0.01$ & 0.20 \\
POC ${ }^{*}$ Gender & 0.00 & 1 & 0.00 & 0.00 & 0.98 & 0.00 \\
Error & 21.31 & 45 & 0.47 & & & \\
Total & 914.92 & 49 & & & & \\
\hline
\end{tabular}

BREA M. BANKS, Ph. D. is an Assistant Professor of Psychology at 
Illinois State University and is a Licensed Clinical Psychologist in the state of Illinois. Her research interests include the cognitive consequences of microaggression and student of color experiences in higher education. Email: bmbanks@ilstu.edu; Twitter:@DocBanks4

DAVID FRANCIS ADAMS, Ph.D. is a Licensed Clinical Psychologist at Illinois State University's Student Counseling Services. His research interests include innovative ways college counseling centers can address student needs, counseling services and retention of underrepresented students, and programming to address racial microaggressions on campus. Email: dfadams@ilstu.edu

CEDRIC WILLIAMS, Ph.D. is a Consulting Psychologist and serves as the Founder \& CEO of Legacy Consulting \& Research Group LLC. His consulting and research services for teams and organizations focuses on multicultural competence, resilience, and occupational thriving. Email: cwilliams@legacycrg.com

DAKESA PIÑA, Ph.D. is a Staff Counselor and Instructional Assistant Professor at Illinois State University. She is also a Licensed Marriage and Family Therapist in the state of Illinois.

Email: ddpina@ilstu.edu 